\title{
Yabancı Dil Öğretiminde Kısa Metinlerin Kullanımı ve Önemi
}

\author{
Yüksel Ersan* \\ Uşak Üniversitesi, Fen Edebiyat Fakültesi, Uşak.
}

\begin{abstract}
$\ddot{O} z$
Ülkeler arasında sinırların kalktığı günümüz dünyasında, yabancı dilin önemi dün olduğu gibi, bugün de bir kat daha artmıştır. Üniversiteler farklı coğrafyalardan öğrenci kabul etmekte, ülkelerin ekonomilerinde turizm oldukça fazla yer tutmakta, dünyada hızl ve büyük bir devinim yaşanmaktadır. Dil öğretiminde temel hedef, dört beceriyi -okuma, yazma, konuşma, dinleme- yeterince geliştirmektir. Bu hedefe ulaşmada edebiyat ve edebiyatın ürünü olan kısa metinler -kısa hikâye, masal, fabl, bulmaca, günlük vb.- öğrencilerin becerilerinin gelişmesinde bir araç olarak kullanilabilmektedir. Çünkü Edebiyat, öğrencilerin hem bir ülkenin kültürünü, dilini, insanin anlamalarına yardımci olmakta, hem de bireysel olarak kendi "duygu-akıl dengesine ulaşmalarımı" sağlamaktadır. Dil öğretiminde öğretmene önemli bir rol düşmektedir. Metinleri hazırlarken öğretmen hedef dili temel almalıdır. Çünkü (özellikle Türkiye gibi hedef dilden çok uzakta yabancı dil öğrenen) öğrenciler bu dilin kullanımını ancak edebiyat metinleri yoluyla deneyimleyebilmekte ve o ülkenin dili, yaşamı ve kültürü hakkında bilgiler edinebilmektedirler. Bu çalışmamızda Edebiyatın kısa türlerinin dil öğretiminde kullanımı hakkında bilgi vererek olumlu ve olumsuz yönlerini ortaya koyacak, yabancı dil öğrenen öğrencilere nasıl faydalı olabileceğimizi araştıracağız.
\end{abstract}

Anahtar Sözcükler: Yabancı Dil Öğretimi, Dil Öğretimi Yöntemleri, Edebiyat, Kültür, Kısa Metinler

\section{Use and Importance of Short Texts in Foreign Language Teaching}

\section{Abstract}

In our contemporary world, in which the boundaries have been demolished among the countries, the importance of a foreign language has been doubled as it was in the past. The universities have been accepting students from different geographies, tourism has had an important place in national economy and there have been a swift and great mobility in the world. The main target in language teaching is to develop the four skills-reading, writing, speaking and listening. To achieve this goal literature and as a product of it short texts - short story, fairy tale, fable, puzzle, diary etc. can be used as a learning tool for developing students' language skills. Because, literature both helps students to understand the culture, the language, the folk of a country and makes them to achieve personal balance between emotion and reason. In language teaching there is a big role for the teacher. When preparing the texts, the teacher should base the target language. Because the students (particularly the ones- like Turkish, living far away from the target language) can only experience the use of target language through literary texts and so they can get information about the language, life style and culture of that country. In this study, we give information about the use of short literary texts in language teaching and investigate how they can help the students learning a foreign language by putting forward their pros and cons.

Keywords: Foreign Language Teaching, Language Teaching Methods, Literature, Culture, Short Texts 


\section{GİRIŞ}

Günümüzde neredeyse sınırların kaldırıldığı bir dünyada kendi coğrafyası içinde kapalı bir toplum olarak yaşamak artık mümkün değildir. Yabancı dil öğrenmenin ve öğretmenin önemi dün olduğu gibi bu gün de günceldir ve açıktır. Artık iş dünyasında bir yabancı dili herkesin bildiği varsayılmakta, ikinci hatta daha fazla yabancı dil bilen kişiler tercih edilmektedir. Globalleşen dünyada ekonomide turizmde, eğitimde geniş anlamda bir küreselleşme söz konusudur. Böyle bir ortamda yabancı dilin, öğreniminin ve öğretiminin de gittikçe artan bir önem kazandığ görülmektedir. Artık önceden kullanılan geleneksel öğretim yöntemlerinin yanı sıra iletişimin ön planda olduğu günümüz dünyasında daha yeni metotlardan faydalanarak sosyal ve kültürel dünyaya uyumlu bireyler yetiştirmek daha bir önem kazanmıştır.

Yabancı dil öğretiminde de öğrenci merkezli, iletişimin ön planda olduğu, kültürleri ve toplumları birbirine yaklaştıran, adeta bir köprü görevi gören aydın bir toplum yetiştirmek ilk hedeftir. Yabancı dil öğrenen ve bilen kimseler, kültürler ve toplumlar arasında bir köprü oluşturmakta, ülkesinin diline ve kültürüne farklı bir bakış açısı edinmekte, aynı zamanda kendi kültüründen ve dilinden kopmadan köprü vazifesi gören aydın bireyler olmaktadır. Bu bireyler, kendi kültürlerinin farkına varmakta, başka bir kültürü yakından tanımakta, bizden olmayanı anlamamızı sağlamaktadırlar.

Günümüz dil eğitiminin başlıca hedefleri arasında iletişimin yanında, karşı tarafın dinini, dilini, kültürünü, tarihini, edebiyatını kısaca yaşam biçimini anlamak için önemli bir görev üstlenmektedir. Yabancı dil öğrenmenin bu kadar önemli olmasına binaen birçok yeni yöntemler geliştirilmiş, insanların ilgisini sürekli canlı tutmak için yeni materyaller de kullanılmaya başlanmıştır. Edebiyat ve edebiyatın ürünleri olan materyaller de dil öğretiminde ayrıcalıklı bir yer tutmaktadır. Yabancı dil öğretiminde edebi metinlerle çalışmak, edebi metinleri kullanmak önemlidir, çünkü edebi metinlerin içeriği de yöntem ve teknikleri de dil öğretimi yöntem ve derslerine uygundur. Bunu dil öğretiminde dört becerinin geliştirilmesinde de rahatlikla kullanabiliriz. Edebi metinler aynı zamanda öğrencilere hedef dilin yanında hedef kültürü de göstermekte ona kaynaklık etmektedir. Edebi metinlerin derslerde kullanılmasına aşağıda verilen gerekçeleri örnek olarak gösterebiliriz (Arak, 2001: 4);

- Edebiyat ilginç öğrenme ortamları için büyük bir potansiyel oluşturmaktadır. Kısa bir hikâye, roman veya şiir her yerde okunabilir. Buna karşın dilbilgisi kitaplarından öğrendiğimiz diyalogları gerçek hayatta kullanmak çok da kolay değildir.

- Edebi metinlerle çalışmak otantik iletişim olanakları sağlamaktadır. Bir diğer deyişle size gerçek dünyayla örtüşen gerçekçi ortamları hazırlar.

- Edebi metinler kültür ortamlarını yakından tanıttığından dil öğrenenlerin sosyal becerilerini geliştirmelerine, eğitim öğretimlerine de doğrudan katkıda bulunur. 
Gerhardt Helbig de "Yabancı Dil Olarak Almanca" adlı eserinde edebi metinlerin kullanımı için değişik nedenlerden bahseder. Bunlar (Helbig, 2001: 1334);

- Okuma sevincini artırır,

- İletişim için bir fırsat sunar,

- Bilişsel, sosyal ve duygusal yeterlilikleri teşvik etmektedir.

Gerçekten de öğretmen yabancı dil öğretimi dersinde edebi metinleri itinayla seçer, hazırlar ve derse adapte edebilirse, ders kitaplarındaki kuru metinlerden daha etkili, anlamlı ve öğretici olabilmektedir. Çünkü öğrenciler bu tür çalışmalara aktif olarak katılabilmekte, kendilerini yaratıcı bir biçimde ifade edebilmektedir. Yeteneklerini geliştirmekte, empati kurabilmekte edebiyat sayesinde farklı bir bakış açısından bakabilmektedir.

Yabancı bir dili meslek olarak edinecek öğrencilerde ise, o dili öğrenme ve öğretme süreçlerinde dilbilgisini doğru kullanma olmazsa olmazdır. Bu durum yabancı dil sınıflarında edebi metinlerin seçimini ve öğrenimini daha da ön plana çıkarır ki her edebi metin bu süzgeçten geçtiği için tam da kullanıma uygundur. Ancak sebep ne olursa olsun edebi metinler yardımıyla dil öğretimi hatta dil yoluyla edebi metinlerin öğrenilmesi ya da öğretilmesi gibi her durumda da edebiyat ve kısa metinler öğrenci için faydalı bir kaynak teşkil etmektedir.

\section{TÜRK EĞİTIM SISTEMININ GENEL AMAÇLARI VE DİL ÖĞRETIMININN TÜRK MİLLI EĞİTIM SISTEMINDEKİ YERİ} fertlerini,

Türk Milli Eğitim Sisteminin genel amaçları arasında: “Türk Milletinin bütün

1. (Değiişik: 16/06/1983-2842 S.K./1. Md.) Atatürk ink1lâp ve ilkelerine ve Anayasada ifadesini bulan Atatürk milliyetçiliğine bağlı: Türk Milletinin millî, ahlâkî, insanî, manevî ve kültürel değerlerini benimseyen, koruyan ve geliştiren; ailesini, vatanını, milletini seven ve daima yüceltmeye çalışan; insan haklarına ve Anayasanın başlangıcındaki temel ilkelere dayanan demokratik, lâik ve sosyal bir hukuk Devleti olan Türkiye Cumhuriyetine karşı görev ve sorumluluklarını bilen ve bunları davranış haline getirmiş yurttaşlar olarak yetiştirmek;

2. Beden, zihin, ahlâk, ruh ve duygu bakımlarından dengeli ve sağlıklı şekilde gelişmiş bir kişiliğe ve karaktere, hür ve bilimsel düşünme gücüne, geniş bir dünya görüşüne sahip, insan haklarına saygılı, kişilik ve teşebbüse değer veren, topluma karşı sorumluluk duyan; yapıcı, yaratıcı ve verimli kişiler olarak yetiştirmek;

3. İlgi, istidat ve kabiliyetlerini geliştirerek gerekli bilgi, beceri, davranışlar ve birlikte iş görme alışkanlığı kazandırmak suretiyle hayata hazırlamak ve onların, kendilerini mutlu kılacak ve toplumun mutluluğuna katkıda bulunacak bir meslek sahibi olmalarını sağlamak; 
Böylece, bir yandan Türk vatandaşlarının ve Türk toplumunun refah ve mutluluğunu artırmak; öte yandan millî birlik ve bütünlük içinde iktisadî, sosyal ve kültürel kalkınmayı desteklemek ve hızlandırmak ve nihayet Türk Milletini çağdaş uygarlığın yapıcı, yaratıcı, seçkin bir ortağ yapmaktır." Şeklindedir (http://personel.meb.gov.tr, 2017).

Bunun dışında 5. maddede ise daha özele girerek yabancı dil eğitimi ve öğretiminin amacı betimlenmiştir. Buna göre:

“MADDE 5 - (1) Örgün, yaygın ve uzaktan öğretim kurumlarındaki yabancı dil eğitimi ve öğretiminin amac1, Millî Eğitimin genel amaç ve temel ilkelerine uygun olarak okul ve kurumların amaç ve seviyeleri de göz önünde bulundurularak eğitim ve öğretimi yapılan yabancı dilde bireylerin;

a) Dinleme-anlama,

b) Okuma-anlama,

c) Konuşma,

d) Yazma

becerileri kazanmalarını, öğrendiği dille iletişim kurmalarını ve yabancı dil öğretimine karşı olumlu tutum geliştirmelerini sağlamaktır." şeklindedir (http://mevzuat.meb.gov.tr, 2017).

Her iki maddede de görüldüğü gibi genel amaçlarda ve özel amaçlarda öğrencilerin gelmeleri gereken seviye ve öğretmenlerin hedefleri genel anlamda belirtilmiştir. Ancak bu amaçlar doğrultusunda özel ve devlet okullarında dil eğitimi yapılmaktadır. Hedefe ulaşıldığında bu okulları bitiren her Türk Öğrencisi yabancı bir dilde "dinleme, okuma, konuşma, yazma" gibi dört temel beceriyi edinmiş olarak okullarını bitirmiş olacaklardır.

\section{DİL ÖĞRETIMINNDE EDEBİ METINLERİ KULLANAN YÖNTEMLER}

Yabancı dil öğretimi ve nasıl öğretileceği konusu eskiden olduğu gibi günümüzde de farklı bakış açılarından değerlendirilmektedir. Hatta siyasi iktidar ve yöneticiler de zaman zaman olaya farklı pencerelerden bakmaktadır ki, bir dönem Türkiye Ortaöğretim okullarında Yabancı Dil dersleri zorunlu olmaktan çıkartılıp seçmeli statüsüne alınmış bu dönemde birçok öğrenci yabancı dil derslerini seçmeden okullardan mezun olmuşlardır. Günümüzde Türk Milli Eğitim Sisteminin orta dereceli okullarında bir yabancı dil zorunlu (çoğunlukla İngilizce) ikinci yabancı dil seçmeli (İngilizce dışında ikinci yabancı dil, Almanca ilk sırada) olarak okutulmaktadır.

Yabancı Dil öğrenirken var olan birçok yöntemden yararlanılabilir. Her öğretmen bu yöntemlerden kendisi ve öğreteceği kişilere uygun olanı belirler ve birden çok yöntemi kullanabilir, çünkü "bir kişi üzerinde faydalı olabilecek bir yöntem başka bir kişi üzerinde aynı ölçüde başarılı olmayabilir ya da tamamen başarısız kalabilir." (Tarcan, 2004: 6) Dil öğretiminde özellikle de yabancı dil öğretiminde yöntem denilince akla öğrenciyi amaca ulaştırabilmek için hızlı, güvenilir bir yol anlaşılmaktadır. Asıl olan öğretmenin kullanacağı yöntemin faydalarını, sınırlarını, temel prensiplerini ve en 
önemlisi de kullanım şeklini ve prensiplerini iyi bilmelidir. Birden fazla yöntemin ortaya çıkmasının esas sebebi de bir yöntemin eksikliklerini veya yetersizliğini ortadan kaldırmak için yeni bir yöntemin uygulanmasıdır ki, bunun sonucunda alternatif yöntemler dil öğretimine kazandırılmıştır. Bu kadar çok yöntemin olması da ideal bir yöntemin olmamasını gösterir. Bu da öğrencilerin, öğrenme ortamının, hedeflerinin, sosyal ve ekonomik durumun vb. farklı olması sonucudur.

Yabancı dil öğretirken araç olarak kullanılan kısa metinlerden kastımız genel anlamda başlangıçta (kısa hikâye, masal, bilmece-bulmaca, anı, günlük, şiir vs.) edebiyattaki kısa türlerdir. Gerçi dil öğretiminin ileriki zamanlarında uzun türlerde araç olarak kullanılabilmektedir.

Yabancı dil öğretiminde kullanılan birçok yöntem edebi ürünleri bir araç olarak kullanmaktadır. Öğretmen hedef kitleye göre yöntemini daha önceden belirler ve materyallerini ona göre seçer ve geliştirir. Eğer ilkokul düzeyinde dil öğretecekse farklı, üniversite düzeyinde öğretecekse farklı edebi kısa türleri kullanabilir. Dil öğretim yöntemlerini Nilüfer Bekleyen (Bekleyen, 2015: 6) üç ana grupta siniflamaktadır.

1) 20. Yüzyıldan Önce Dil Öğretimi

2) 20. Yüzyılda Dil Öğretimi

3) 21. Yüzyılda Dil Öğretimi

Biz burada dil öğretim yöntemlerine kronolojik yaklaşıp, döneme damga vuran en çok kullanılanları dikkate alarak kısa edebi metinleri kullanmalarına bakmak istiyoruz.

\subsubsection{Yüzyıldan Önce Dil Öğretimi}

Burada Fransız C. Marcel, P Passy, İngiliz Prendergast, Sweet ve Alman Wilhelm Vietor gibi dilbilimcileri görmekteyiz. Bu dilbilimcilerin bazıları yabancı dili de Anadili öğrendikleri gibi öğreneceklerini düşünmekteydi ve günümüze kadar gelen Dilbilgisi-Çeviri yöntemini, özellikle Latince öğrenirken, benimsiyorlardı. Bu yönteme göre yazma ve okuma becerilerine ağırlık verilmekte, bu becerileri geliştirici etkinlikler yapılmaktadır. Burada "metnin içeriğine fazla önem verilmez. Ancak, metnin içeriği, dilbilgisi ve kelime analizi için bir alıştırma niteliğindedir. Yani metinde anlatılanlardan çok, içindeki cümle kalıpları, kelimeler ve kelime grupları önemlidir. Çünkü dilin kurallarını öğretmek ve bu kurallar aracılığıyla doğru çeviri yapabilmek bu yöntemin temel amacıdır" (Bekleyen, 2015: 26).

Görüldüğü gibi edebi metin burada amaç değil araçtır. Edebi metinlerin yardımıyla öğrencilerin okuduğunu anlama becerisi, kelime bilgisi, yazma becerisinin geliştiği söylenebilir. Edebi metinler yardımıyla öğrencilerin çeviri becerilerinin gelişiminin yanında okuma becerileri gelişecek okuma metinlerinin sonunda;

- okuduğunu anlama,

- çıkarım,

- kendi deneyimleriyle metin arasında bağlantı kurmaya yardımcı olacak türden sorulara 
cevap verebileceklerdir. Aynı zamanda kelime bilgileri gelişecek, eş ve zıt anlamlı kelimeler vasıtasıyla kelime dağarcıkları zenginleşecektir. Burada hedef dil ile anadil arasında benzeyen kelimeler de yardımcı olabilmektedir.

Dilbilgisi kuralları tümdengelim yöntemiyle öğrencilere gösterilir. Örneğin $S+$ $\mathrm{V}+\mathrm{O}$ şeklinde bir cümlenin oluşumunun metindeki karşılıkları bulmaları istenebilir. Aynı zamanda boşluk doldurma yöntemiyle cümlede boşluklar bırakılarak çoktan seçmeli şekilde buralara öğrencilerin doğru cevapları koymaları istenilebilir. Öğrencilerin metin içindeki kelimelerin anadildeki karşılıkları ezberlemeleri istenilebilir ve bunları yeni cümlelerde kullanmaları yoluyla pekiştirmeleri sağlanabilir.

Aynı zamanda öğrencilerin yazmaları da geliştirilebilir, öğrendikleri kelimeler yardımıyla okuma metninin teması, konusu, başlı̆̆ı ile ilgili yazma denemeleri yaptırılabilir. Bu yöntemle öğrenci “ okuma ve yazma becerileri yönünden ilerleme kaydeder. Fakat konuşma ve dinleme becerileri yönünden problem yaşar" (Demirel, 2010: 40).

\subsection{Yüzyılda Dil Öğretimi}

19. Yüzyılın sonlarına doğru çok fazla eğitimci bu yönteme karşı çıkmaya başladı ve Düzvarım Yöntemi (Direct Method) tartışılmaya başlandı. Burada derse başlarken öğretmen öğrencilere ilginç bir diyalog, kısa bir hikâye ya da fıkra anlatmaktadır. Bu yöntemle yabancı dil öğrenmenin ana dili öğrenmeyle aynı olduğu ileri sürülmektedir ve öncelikle sözlü öğretim yapılmaktadır (Hengirmen, 2006: 19). Dilin telaffuz özellikleri ve öğrenci ön plandadır. “Okuma parçaları ve okuma alıştırmalarında kullanılan metinlerin hedef dili konuşan ülkenin kültürünü ve günlük yaşamını yansıtmasına özen gösterilir" (Demirel, 2010: 40). Öğretmen merkezli olan bu yöntem öğretmenin yeteneklerine ve o dili kullanma becerisine doğrudan bağlıdır ki "sınıfta anadilin konuşulmasını ve çeviri yapmayı yasaklar. Dilbilgisi açıklamalarına yer vermeyen bu yöntem iyi eğitilmiş öğretmenlerle sınırlı sayıda öğrenciye eğitim veren özel kurslarda çok başarılı olurken diğer okullarda aynı başarıyı gösterememiştir (Bekleyen, 2015: 8). Ancak sınıf mevcutlarının kalabalık olduğu ve yeterince iyi eğitim alamamış öğretmenlerin bulunduğu devlet okullarında başarılı olamamıştır.

Bu yöntemin haricinde bu yüzyılda 1950'lerde İşitsel Dilsel Yöntem (AudioLingual Method), 1970'lerde Bilişsel Kod Yaklaşımı (Cognitive - Code Approach) ön palana çıkmıştır. Daha sonra 1970'lerden 1990'lara kadar kullanılan İletişimsel Yöntem ortaya çıkmıştır ki bu yöntem birçok eğitim kurumunda başlıca dil öğretim yöntemi olarak kullanılmıştır. Bu yöntemin amacı dili iletişim odaklı kültürü de birleştiren etkinliklerle öğretmektir. Sonuçta öğrenci dili kullanabilmek için hem yetenek hem de bilgi sahibi olacaktır. Öğrenci bu yöntemde merkezdedir, materyaller, ortam ve aktiviteler öğrenci odaklıdır. Hedef dilin yanında hedef kültür de öğretilmektedir.

Edebi metinler olarak röportaj, boşluk doldurma, diyaloglar gibi kısa metinler kullanılabilmektedir. Okuma parçalarının daha kolay anlaşılabilmesi için öğrencilere 
anahtar kelimeler ve metindeki başlıca kavramlar verilebilir. Diyalog çalışmalarıyla öğrenciler kendi aralarında iletişim kurarlar.

\subsubsection{Yüzyılda Dil Öğretimi}

Dil öğretiminde ideal bir öğrenme yöntemi olmadığı için yeni yöntem arayışları devam etmiştir, ancak iletişimsel yöntemin etkileri bu yüzyılda da devam etmektedir. “Günümüzde yaşanan dönem Güncel İletişimsel Dil Öğretimi dönemidir." (Bekleyen, 2015: 14) Artık önceki dönemlerdeki katı görüş ve kurallardan sıyrılınmış, öğretmenler ve öğrencilerin daha serbest hareket ettiği, öğrenci merkezli bir dil öğretimi sistemi uygulanmaktadır.

İletişim teknolojilerinin ve elektronik öğrenme ve materyallerin geliştiği dünyamızda öğretmen öğrenci ilişkileri gelişmiş, öğretirken kendi alanı ile ilgili daha fazla bilgi kazanır olmuşlar, yaşam boyu öğrenmeyle öğretmenler öğrencilerine örnek oluşturmaktadırlar. Derslerin işlenişinde tek bir yöntem kullanılmamakta, öğrencilerin yaşlarına, sosyal ve eğitim durumlarına, kişisel özelliklerine göre sınıflar oluşturulmakta, bu durumlar dikkate alınarak dil öğretimi yapılmaktadır. Artık öğretmenler kendilerine ve öğrencilerine hangi yöntem daha uygunsa onu seçebilmekte, birden fazla yöntemden yararlanabilmekte, kendi ortamlarına ve kişisel özelliklerine en uygun süreci takip etmektedirler.

Günümüzde dil öğretiminde birçok yerde ve öğretmenin kullandığ1 Güncel İletişimsel Dil Öğretimi yöntemine göre örnek bir ders planı kısa metinlerden "Günlük" kullanılarak aşağıda çıkarılmıştır.

\section{4. ÖRNEK BIIR DERS PLANI}

Dersin Düzeyi : : 2

Dersin Konusu : :Bir günün Anlatılması

Dersin Amacı : : 80-100 sözcükle öğrenciler sıradan bir günde yaptıklarını Anlatacaklar

Etkinlikler : Öğrenciler teknolojinin de yardımıyla;

1) Bir günü içeren kısa bir film izleyebilirler,

2) Bununla ilgili yeni kelimeler öğrenirler,

3) Etkinlikte geçen zaman bildiren kelimeleri kullanacaklar ve tanıyacaklar,

4) Öğretmen kontrolünde günün bölümlerinde neyi yapıp neyi yapmadıklarını öğrenirler,

5) Örnek bir metinle bir günü işleyen kısa bir okuma parçasını (Günlük) okuyup kısa soruları cevaplayabilirler,

6) Bundan sonra kendilerinin bir gününü anlatan bir metin yazabilirler,

7) Konuyla ilgili yakınlarından birinin bir gününü öğrenip, not alarak o kişiyi sözlü olarak tanitabilirler. 


\section{Materyaller:}

1) Kısa Film (Bir günü anlatan),

2) Öğretmenin hazırlayacağı konuyla ilgili Powerpoint sunusu,

3) Öğrencilerin hazırlayabilecekleri günü anlatan sunu,

4) Ders Kitab1,

5) Okuma parçası (Bir günü anlatan Günlük).

\section{SONUÇ}

Yabancı dil öğretiminde öğrencilerin öğrendikleri dilin farklı yapılarıyla ve kültürüyle karşılaşabilecekleri yer edebiyatın ta kendisidir. Öğretmenlerin yardımcısı, teknolojinin yanında edebi metinler olabilir. Edebi metinler ile çalışma, öğrenmenin en başından en sonunda kadar yapılabilmekte, öğrenci düzeyine uygun metinler seçilerek etkin ve aktif olarak kullanılabilmektedir. Öğretmenin sınıfa getireceği edebi metinle, okuma başta olmak üzere yazma, konuşma hatta edebi metnin ilgili dildeki konuşmacı tarafından kayda alınmış görsel ve işitsel şekliyle dinleme becerilerini geliştirmeye yönelik çalışmalarla öğrencilere edebiyatla bir bağ kurma imkânı verilmiş olur. Yabancı dil öğrenen kişiler, ana dilinin ve kültürünün dışında ikinci bir kültür ve dille köprü kurar, ülkesinin diline ve kültürüne başka bir açıdan bakma imkânı bulur (Aytaç, 1990: 149).

Görüldüğü gibi edebi metinler, dil öğrenmenin bütün aşamalarında rahatlıkla kullanılabilmektedir. Edebi metin burada amaç değil bir araçtır, öğrencilerin kelime bilgisi ve dilbilgisinin genişlemesine katkı sağlamaktadır. Dil öğretiminde metinler gerekirse ihtiyaca göre kısaltılabilir, genişletilebilir hatta değiştirilebilirler, öğrencilerin kendi hayal dünyalarına göre şekil alabilirler ve farklı yorumlanabilirler. Ancak edebi metnin araç olmasının dışında amaç olduğu durumlar olursa öğrenci edebi metin yoluyla dil öğretimi değil dil yoluyla edebi metin öğretimi durumuna girer ki bu gibi durumlarda amacın dışına taşılır ve hedefe ulaşmak mümkün olmayabilir. Bundan öğretmenin kaçınması gerekir ve en başından hedeflerini belirlerken bunu tespit etmesi gerekmektedir.

Kanımızca böyle geniş açıdan bakılabilen özgür, katılımcı ve öğrenci merkezli dil öğretim şekliyle edebi metinlerin araç olarak kullanıldığı bir dil dersi verimli, başarılı ve tatminkâr olacaktır.

\section{KAYNAKÇA}

Aktaş, T. (2005). Yabancı Dil Öğretiminde Illetişimsel Yeti, Journal of Language and Linguistic Studies, Vol. 1, No. 1, Konya.

Arak, H. (2013). Yabancı Dil Öğretiminde Edebiyatın Yeri, Farklı Boyutlarıla Yabancı Dil Öğrenimi ve Öğretimi, Yusuf Şahin Ed., Eğitim Kitabevi Konya S.107-120.

Armağan, E. A \& Şavlı, F. (2015). Yabancı Dil Eğitiminde Edebi Metinler Kullanımı, International Journal of Languages and Teaching, Mannheim, S. 885-893.

Aytaç, G. (1990). Edebiyat Yazıları I, Gündoğan, Ankara.

Bekleyen, N. (2015). Dil Öğretimi, Pegem Akademi, Ankara. 
Demirel, Ö. (2010). Yabancı Dil Öğretimi, Pegem Akademi Yayıncllı, Ankara

Froidevaux, G. (2003). Vom Nutzen der Literatur für das Lernen einer Fremdsprache, Zeitschrift: Babylonia, Volume 3 - 4, S. 81 - 86.

Grujičić, M. (2012). Literatur im Unterricht: Kulturvermittlung unter Berücksichtigung der Literarizität Komunikacija i kultura online, Godina III, broj 3 http://www.komunikacijaikultura.org/KK3/KK3Grujicic.pdf 06/09/2017

Hengirmen, M. (2006). Yabancı Dil Öğretim Yöntemleri ve Tömer Yöntemi, Engin Yayınevi, Ankara http://mevzuat.meb.gov.tr/html/26184_1.html 30.08.2017

http://personel.meb.gov.tr,/daireler/mevzuat/mevzuatlar/milli_egitim_temel_kanunu_1739.pdf 30/08/2017.

Jašová, M. (2009). Arbeit mit literarischen Texten im DaF Unterricht am Beispiel eines Textes von Christine Nöstlinger, $\quad$ https://is.muni.cz/th/160341/pedf m/Diplomova prace.pdf 06/09/2017

Memiş, R.M \& Erdem, M.D. (2013). Yabancı Dil Öğretiminde Kullanılan Yöntemler, Kullanım Özellikleri ve Eleştiriler, Türkish Studies, Ankara, Volume 8/9, S. 297-318

Papajová, A. (2013). Verwendung des literarischen Werks Simple Storys im Unterricht Deutsch als Fremdsprache, Brünn

Takkaç, M. (1997). Yabancı Dil Öğretiminde Temel Becerilerin Geliştirilmesi İçin Edebiyat Metinlerinin Kullanımı, Atatürk Üniversitesi Türkiyat Araştırmaları Dergisi, Erzurum, Sayı.8, S.43-50

Tarcan, A. (2004). Yabancı Dil Öğretim Teknikleri, Nobel Yayıncllık, Ankara

Ünal, D. Ç. (2005). Yabancı Dil Ögretiminde Ed Eb İ Metinler: Yenilikçi Yaklaşımlara Geçiş Süreci Ve Gerekçeleri, Hareıtepe Üniversitesi Eğitim Fakültesi Dergisi (1l. U. Journal of Education) 29: 203-212

Wicke, R.E. (2014). Werkzeuge zur Arbeit mit Literarischen Texten, Hueber, München 